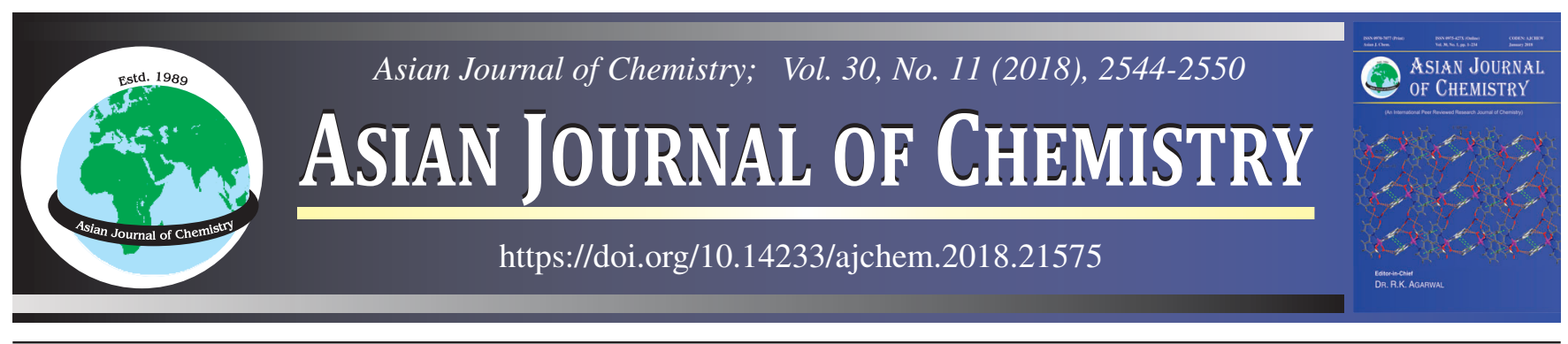

\title{
Enhanced Photocatalytic Activity of Manganese-Doped Cerium Oxide Nanoparticles under Visible and UV Irradiation
}

\author{
Shah Raj Ali, Rajesh Kumar and Mahesh Chandra Arya*
}

Department of Chemistry, DSB Campus, Kumaun University, Nainital-263 002, India

*Corresponding author: E-mail: mcarya181@gmail.com

Received: 12 July 2018; Accepted: 17 August 2018;

Published online: 27 September 2018;

AJC-19109

\begin{abstract}
Manganese-doped cerium oxide nanoparticles were synthesized in different concentrations (3 and 5 mol $\%$ ), by simple aqueous coprecipitation method by adding manganese chloride to cerium(III) nitrate hexahydrate. The synthesized nanoparticles were characterized by powdered XRD measurements, EDAX, SEM, TEM and UV-visible spectroscopic techniques. Powder X-ray diffraction results revealed the phase purity with fluorite structure. EDAX confirmed the doping of manganese in the cerium oxide lattice at different concentrations. Spherical shape of the synthesized particles with fair agglomeration was revealed by SEM analysis. The morphology was further confirmed by TEM analysis which asserted the average particle size to be $12-15 \mathrm{~nm}$. Remarkable red shift in the band gap of manganese-doped cerium oxide nanoparticles was observed by UV-visible spectroscopic analysis. Photocatalytic activity of the pure and $\mathrm{Mn}^{-d o p e d ~} \mathrm{CeO}_{2}$ nanoparticles was evaluated by studying degradation of anthraquinone dye remazol brilliant blue R under visible and UV irradiation. The $3 \mathrm{~mol} \% \mathrm{Mn}$-doped $\mathrm{CeO}_{2}$ nanoparticles exhibited 61.7 and $62.4 \%$ photocatalytic efficiency under visible and UV irradiation, respectively and $5 \mathrm{~mol} \% \mathrm{Mn}$-doped $\mathrm{CeO}_{2}$ nanoparticles showed photocatalytic efficiency of 62.4 and $67.7 \%$ under visible and UV irradiation, respectively. The present study suggests a facile method to narrow the band gap of cerium oxide nanoparticles and making it more efficient photocatalyst by doping it with Mn ions.
\end{abstract}

Keywords: Manganese-doped cerium oxide nanoparticles, Anthraquinone dye, Remazol brilliant blue R, Photodegradation.

\section{INTRODUCTION}

With the development of science and technology, water pollution has become a serious concern among the scientific community. Application of photocatalytic technique to degrade the organic water pollutants has been one of the main ecofriendly ways of water treatment. Semiconductor based photocatalysts have been under extensive study and research of water treatment $[1,2]$. Among these, cerium oxide nanostructures have got the prime focus of the researchers as photocatalyst, though these have been explored for their application in the various fields as catalyst [3], optical film material [4], automotive exhaust catalyst [5], ultraviolet shielding material [6], optoelectronics, microelectronics and gas sensors [7]. The band gap of $3.2 \mathrm{eV}$ makes $\mathrm{CeO}_{2}$ an efficient absorbent in $\mathrm{UV}$ region and a potential photocatalyst. In fact, nanostructured $\mathrm{CeO}_{2}$ has emerged as the substitute for the conventional $\mathrm{TiO}_{2}$ among the researchers for photocatalytic study [8]. $\mathrm{CeO}_{2}$ nanostructures have been widely explored for their photocatalytic activity towards environmental remediation in general and wastewater treatment in particular.

Literature reveals the use of $\mathrm{CeO}_{2}$ nanostructures in the photocatalytic degradation of dyes viz. degradation of methylene blue using $\mathrm{CeO}_{2}$ nanocrystals [9], Photocatalytic degradation of an aqueous suspension of acridine orange using $\mathrm{CeO}_{2}$ nanoparticles under UV light [10], photocatalytic degradation of congo red [11], photocatalytic degradation of rhodamine-B dye using visible light [12]. But the large band gap of $3.2 \mathrm{eV}$ allows only UV radiation-induced photocatalysis in $\mathrm{CeO}_{2}$ and limits its practical application as hardly 3-5\% of solar energy consists of UV-radiation [13]. This has compelled the researchers to devise the strategy to expand the photoadsorption of $\mathrm{CeO}_{2}$ to the visible light region and enhance the photocatalytic activities. Introduction of surface defects is one such method which enhances the photocatalytic activity as it traps the electrons and prevents recombination of electron and holes. In addition, these

This is an open access journal, and articles are distributed under the terms of the Creative Commons Attribution-NonCommercial 4.0 International (CC BY-NC 4.0) License, which allows others to copy and redistribute the material in any medium or format, remix, transform, and build upon the material, as long as appropriate credit is given and the new creations are licensed under the identical terms. 
defects also act as sites for adsorption of the dye molecules available for degradation [14]. The most common strategy adopted by the researchers is the dopant-assisted enhancement of physical properties of $\mathrm{CeO}_{2}$. It includes narrowing the band gap of $\mathrm{CeO}_{2}$ nanoparticles by doping the pristine $\mathrm{CeO}_{2}$ with various metals. A number of metals including transition metal ions including Fe [15], Au [16], Pd- [17], Mn [18], Fe, Ti and Co [7] have been doped with $\mathrm{CeO}_{2}$ nanoparticles to manipulate their band gap and enhance their photocatalytic activity. Among the transition elements, doping of $\mathrm{Mn}$ - increased the photocatalytic activity of doped $\mathrm{CeO}_{2}$ nanoparticles due to decrease in band gap as a result of lower energy of empty $d$-orbitals in Mn than $4 f$ orbitals of Ce [19]. The $4 f$ electronic configuration can enhance transfer of an electron from the adsorbed dye to oxygen species, thus increases the photocatalytic activity [20].

Our present work reports the effect of Mn-dopant concentration on the physical, structural, optical and photocatalytic properties of $\mathrm{Mn}$-doped $\mathrm{CeO}_{2}$ nanoparticles synthesized by a facile aqueous coprecipitation method. The photocatalytic activity of pristine and $\mathrm{Mn}$-doped $\mathrm{CeO}_{2}$ nanoparticles have been investigated towards the degradation of anthraquinone dye remazol brilliant blue $\mathrm{R}$ under visible and UV irradiation. Remazol brilliant blue $\mathrm{R}$ is a reactive dye that contains alkyl sulphonate anchor group. Its non-biodegradability and recalcitrant nature harms aquatic life [21].

\section{EXPERIMENTAL}

High purity analytical grade $\mathrm{Ce}\left(\mathrm{NO}_{3}\right)_{3} \cdot 6 \mathrm{H}_{2} \mathrm{O}, \mathrm{MnCl}_{2}$ and ammonia solution were procured from Ottochemie, India and analytical grade remazol brilliant blue $\mathrm{R}$ was purchased from SRL India. Ethanol was purchased from Molychem, India. Double distilled water was used throughout the experiments.

Synthesis of Mn-doped $\mathrm{CeO}_{2}$ nanoparticles: $\mathrm{Mn}$-doped $\mathrm{CeO}_{2}$ nanoparticles ( 3 and $5 \mathrm{~mol} \%$ ) were synthesized by facile aqueous coprecipitation method. $\mathrm{Mn}$-doped $\mathrm{CeO}_{2}$ nanoparticles $(3 \mathrm{~mol} \%)$ were synthesized by a slow reaction of 0.03 $\mathrm{mol}$ of $\mathrm{MnCl}_{2}$ in $100 \mathrm{~mL}$ water and $0.097 \mathrm{~mol} \mathrm{Ce}\left(\mathrm{NO}_{3}\right)_{3} \cdot 6 \mathrm{H}_{2} \mathrm{O}$ in $100 \mathrm{~mL}$ water. The reactant mixture was heated at $50^{\circ} \mathrm{C}$ for 30 min with constant stirring at $500 \mathrm{rpm}$ followed by addition of $10 \mathrm{~mL}$ of $(30 \%)$ ammonia solution drop by drop till the colour of the reaction mixture changed to dirty grey. The mixture along with the precipitate was heated further at $50{ }^{\circ} \mathrm{C}$ for $4 \mathrm{~h}$ with constant stirring. The dirty grey precipitate formed in the reaction was collected by centrifugation. It was washed several times with water to remove chloride and nitrate ions which was checked in the supernatant solution. After final washing with ethanol, the precipitate was dried at $60^{\circ} \mathrm{C}$ for $2 \mathrm{~h}$ and then annealed at $200^{\circ} \mathrm{C}$ for $2 \mathrm{~h}$ in air at 1 atmosphere. The annealed precipitate was ground and stored in airtight vials for further use. The similar method was followed for the synthesis of $5 \mathrm{~mol} \%$ Mn-doped $\mathrm{CeO}_{2}$ and pure $\mathrm{CeO}_{2}$ nanoparticles taking appropriate masses of $\mathrm{MnCl}_{2}$ and $\mathrm{Ce}\left(\mathrm{NO}_{3}\right)_{3} \cdot 6 \mathrm{H}_{2} \mathrm{O}$.

Characterization: The phase and crystalline structure of the synthesised material was studied with powder X-ray diffraction measurements taken on a Bruker D 8 Advanced diffractometer operating at $40 \mathrm{kV}$ and $35 \mathrm{~mA}$ and having $\mathrm{CuK} \alpha$ radiation $(1.5406 \AA)$. The SEM images of the samples were taken using a
ZEISS (SUPRA). The TEM analysis was carried out on an FEI Tecnai T20 transmission electron microscope with a $200 \mathrm{keV}$ electron source. The UV-visible spectrophotometer (JASCO V670, Japan) was used to record the optical absorption spectrum of the synthesized samples.

Photocatalytic activity evaluations: Photocatalytic activity of pure $\mathrm{CeO}_{2}, \mathrm{Mn}$-doped $\mathrm{CeO}_{2}$ nanoparticles ( 3 and $5 \mathrm{~mol} \%$ ) was evaluated by studying the degradation of remazol brilliant blue R under visible and UV irradiation. Photocatalytic degradation of remazol brilliant blue $\mathrm{R}$ under UV irradiation was carried out in the quartz jacketed cylindrical photochemical reactor having an $125 \mathrm{~W}$ medium pressure mercury vapour lamp as the source of UV radiation with emission maximum in the range $200-500 \mathrm{~nm}$. Photocatalytic degradation under solar radiation was studied on a normal sunny day between $9.30 \mathrm{am}$ to $3.30 \mathrm{pm}$. In each experiment, $100 \mathrm{mg}$ of photocatalyst was dispersed in $100 \mathrm{~mL}$ of $10^{-4} \mathrm{M}$ remazol brilliant blue $\mathrm{R}$ solution and the reaction mixture was agitated in dark for $60 \mathrm{~min}$ to attain the adsorption-desorption equilibrium. Then the reaction mixture was exposed to UV or visible radiation with constant stirring and $5 \mathrm{~mL}$ aliquot was collected at $60 \mathrm{~min}$ interval of irradiation. This sample was centrifuged (2000 rpm, $10 \mathrm{~min}$ ) and filtered to remove the photocatalyst. The residual concentration of the dye was determined in the filtered aliquot. The characteristic absorbance at $593 \mathrm{~nm}$ was used to evaluate the photocatalytic degradation [22]. All the measurements were carried out at room temperature. The efficiency of the photocatalyst was determined in terms of percent degradation of dye (D \%), calculated by using the following expression:

$$
\mathrm{D}(\%)=\frac{\mathrm{C}_{\mathrm{o}}-\mathrm{C}}{\mathrm{C}_{\mathrm{o}}} \times 100
$$

where, $C_{0}$ is the initial concentration of remazol brilliant blue $\mathrm{R}$ solution and $\mathrm{C}$ is its final concentration after degradation [11]. A series of blank experiments were run to measure the removal of dye by adsorption and degradation of dye without illumination.

\section{RESULTS AND DISCUSSION}

Powdered X-ray diffraction: The crystal structure and phase purity of pure $\mathrm{CeO}_{2}$ and $\mathrm{Mn}$-doped $\mathrm{CeO}_{2}$ ( 3 and $5 \mathrm{~mol} \%$ ) were characterized by powdered X-ray diffraction measurements. The results have been shown in Fig. 1. In each case, well defined Braggs' diffraction peaks at $2 \theta$ value $28.9^{\circ}, 33.3^{\circ}$, $47.5^{\circ}, 56.4^{\circ}, 59.3^{\circ}, 69.3^{\circ}$ and $77.1^{\circ}$ corresponding to (111), (200), (220), (311), (222), (400) and (331) planes, respectively were observed. These results are in good agreement with standard XRD data for $\mathrm{CeO}_{2}$ (JCPDS Card No. 43-1002) having a fluorite structure [23] and suggest that synthesised materials, Mn-doped $\mathrm{CeO}_{2}$ ( 3 and $5 \mathrm{~mol} \%$ ) also have the fluorite structure as that of pure $\mathrm{CeO}_{2}$. Absence of any additional peak strongly rules out the presence of any phase other than $\mathrm{CeO}_{2}$. In addition, quite broad and prominent peaks in the powdered X-ray diffraction analysis indicate that the particle size of the synthesised material is in nanometric dimension. The average crystallite size of the $\mathrm{Mn}$-doped $\mathrm{CeO}_{2}$ nanoparticles was determined from the XRD pattern using DebyeScherrer analysis as under: 


$$
\mathrm{D}=\frac{0.9 \lambda}{\beta \cos \theta}
$$

where, $D$ is average crystallite size, $\lambda$ is the wavelength of instrument radiation ( $1.541 \AA$ ), $\beta$ is the full width at half maximum (FWHM) of the most prominent X-ray peak. The average crystallite size was found to vary with dopant concentration which is supported by broadening of the peaks. The average crystallite size was $10 \mathrm{~nm}$ for undoped $\mathrm{CeO}_{2}, 7 \mathrm{~nm}$ for $3 \mathrm{~mol} \%$ and $3 \mathrm{~nm}$ for $5 \mathrm{~mol} \% \mathrm{Mn}$-doped $\mathrm{CeO}_{2}$ nanoparticles. The lattice strain calculated for $3 \mathrm{~mol} \%$ and $3 \mathrm{~nm}$ for $5 \mathrm{~mol} \% \mathrm{Mn}$-doped $\mathrm{CeO}_{2}$ nanoparticles was found to be 0.0219 and 0.0438 , respectively. So, it can be inferred that the decrease in crystallite size with increase in dopant concentration results into increase in the compression strain in the crystallite upon doping [24].

EDX, SEM and TEM analysis: The energy dispersive $\mathrm{X}$-ray spectra of 3 and $5 \mathrm{~mol} \% \mathrm{Mn}$-doped $\mathrm{CeO}_{2}$ nanoparticles

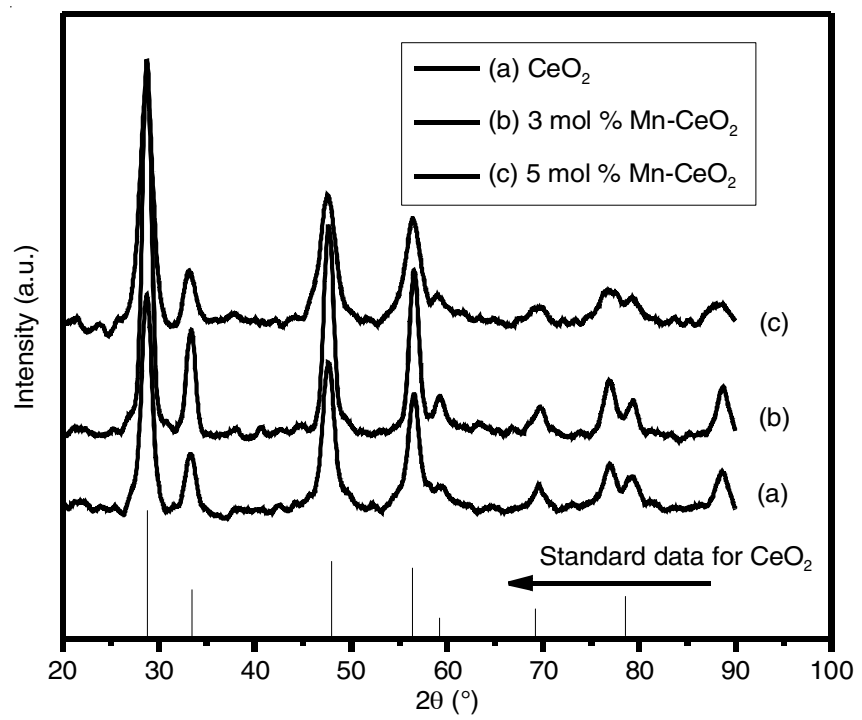

Fig. 1. XRD pattern of pure, $3 \mathrm{~mol} \%$ and $5 \mathrm{~mol} \% \mathrm{Mn}$-doped $\mathrm{CeO}_{2}$

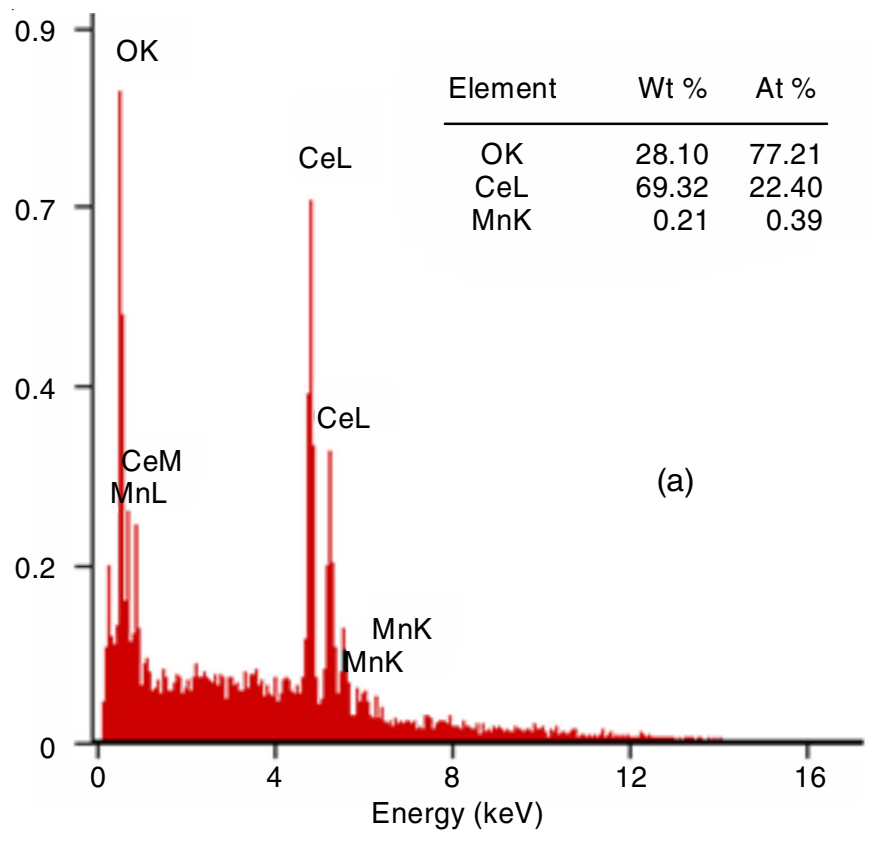

have been shown in Fig. 2. The spectra has the prominent peaks of different intensities corresponding to $\mathrm{Mn}, \mathrm{Ce}$ and $\mathrm{O}$ and clearly showed that the weight $\%$ of $\mathrm{Mn}$ increased with increase in its concentration from 3 to $5 \mathrm{~mol} \%$. However, the absence of peak corresponding to any impurity associated with $\mathrm{Mn}$ in the XRD pattern of 3 to $5 \mathrm{~mol} \%$ Mn-doped $\mathrm{CeO}_{2}$ nanoparticles confirmed that the doped $\mathrm{Mn}$ has occupied the lattice positions in the crystal structure of $\mathrm{CeO}_{2}$ nanoparticles.

The SEM images of Mn-doped $\mathrm{CeO}_{2}$ nanoparticles ( 3 and $5 \mathrm{~mol} \%$ ) are shown in Fig. 3. The images revealed the spherical shape of the synthesized nanoparticles. The SEM images also showed considerable agglomeration among the nanoparticles, which may be attributed to high surface energy in the absence of any capping agent. The TEM images of Mn-doped $\mathrm{CeO}_{2}$ nanoparticles ( 3 and $5 \mathrm{~mol} \%$ ) are shown in Fig. 4. The TEM images revealed that the average particle size was $15 \mathrm{~nm}$ in 3 mol $\%$ and $12 \mathrm{~nm}$ in $5 \mathrm{~mol} \% \mathrm{Mn}$-doped $\mathrm{CeO}_{2}$ nanoparticles. It showed a decrease in average particle size with increase in dopant concentration. Replacement of Ce(IV) with dopant $\mathrm{Mn}$ (II) ions can be the cause of decrease in particle size with increasing percentage of dopant [7].

UV-visible spectral studies: The UV-visible absorption spectroscopic studies of the synthesized $\mathrm{Mn}$-doped $\mathrm{CeO}_{2}$ nanoparticles gave a fair idea of their optical properties. Diffuse reflectance spectra of pure and $\mathrm{Mn}$-doped $\mathrm{CeO}_{2}$ nanoparticles were taken using barium sulphate as a standard. Tauc plots were drawn using the Kubelka-Munk equation [25]. This equation uses the following relation:

$$
(\alpha \mathrm{h} v)^{2}=\mathrm{A}\left(\mathrm{h} v-\mathrm{E}_{\mathrm{g}}\right)
$$

where, $\alpha$ is absorption coefficient, $\mathrm{A}$ is a constant and $\mathrm{E}_{\mathrm{g}}$ is band gap.

The optical band gap of the synthesized nanoparticles was obtained from a Tauc plots drawn between $(\alpha \mathrm{h} v)^{2}$ and photon energy (hv) (Fig. 5a-d). The value of band gap energies was found to be 3.2, 3.0 and 2.8 eV for undoped, $3 \mathrm{~mol} \%$ and $5 \mathrm{~mol}$ $\%$ Mn-doped $\mathrm{CeO}_{2}$ nanoparticles, respectively. These results

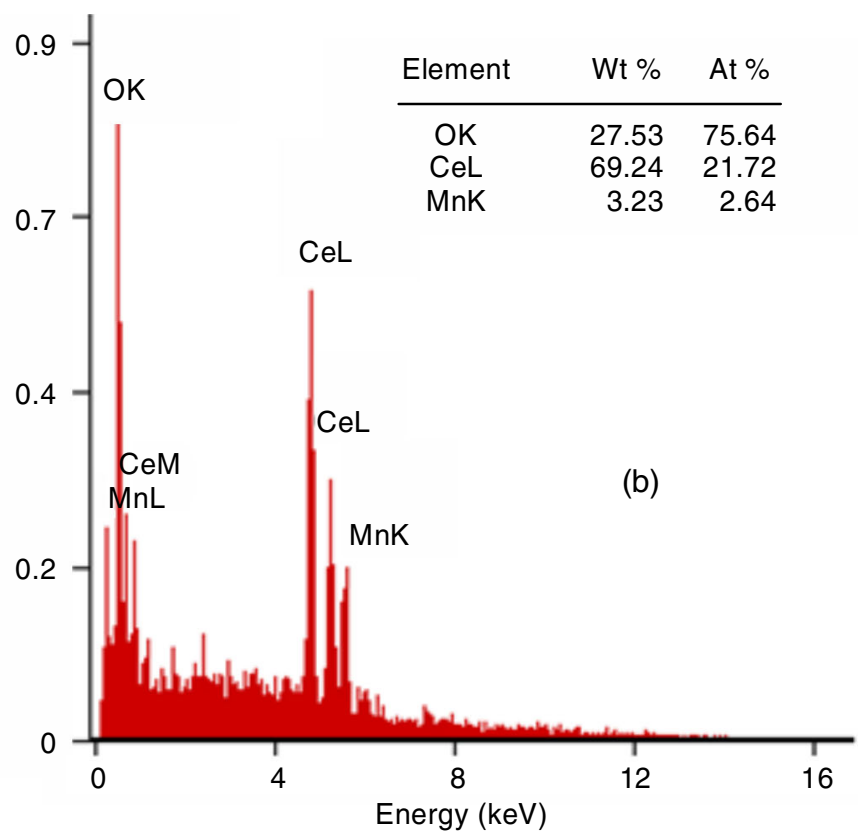

Fig. 2. EDX of (a) $3 \mathrm{~mol} \% \mathrm{Mn}-\mathrm{CeO}_{2}$ (b) $5 \mathrm{~mol} \% \mathrm{Mn}-\mathrm{CeO}_{2}$ 

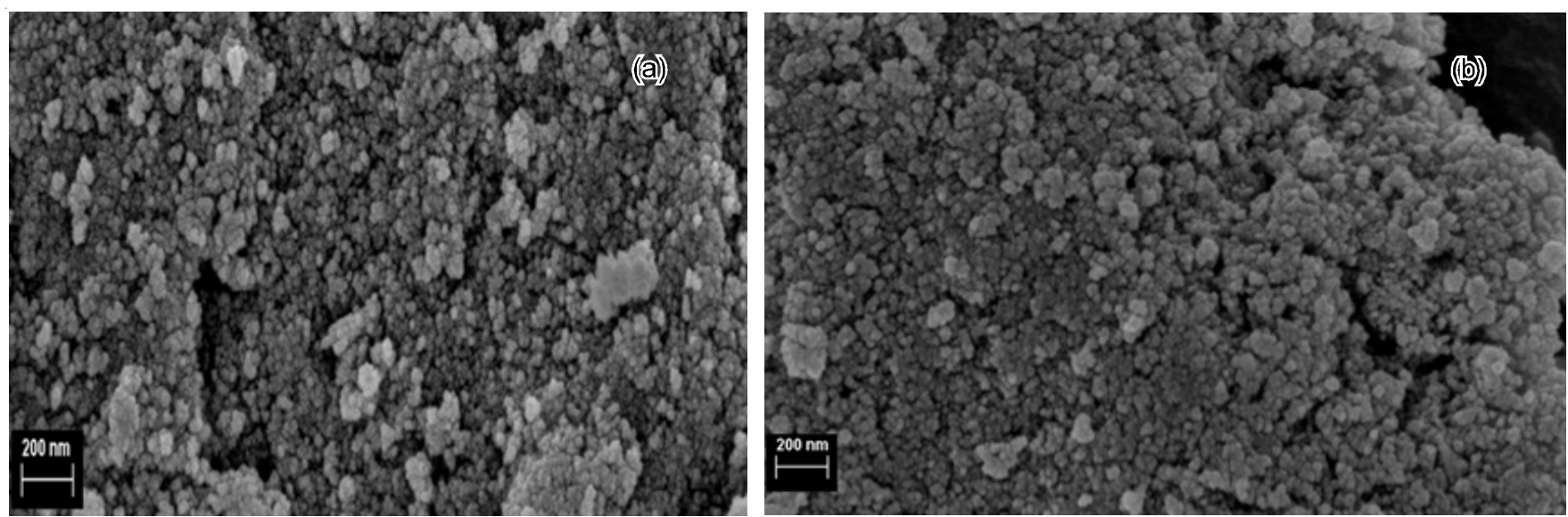

Fig. 3. SEM images of (a) $3 \mathrm{~mol} \% \mathrm{Mn}-\mathrm{CeO}_{2}$ (b) $5 \mathrm{~mol} \% \mathrm{Mn}-\mathrm{CeO}_{2}$
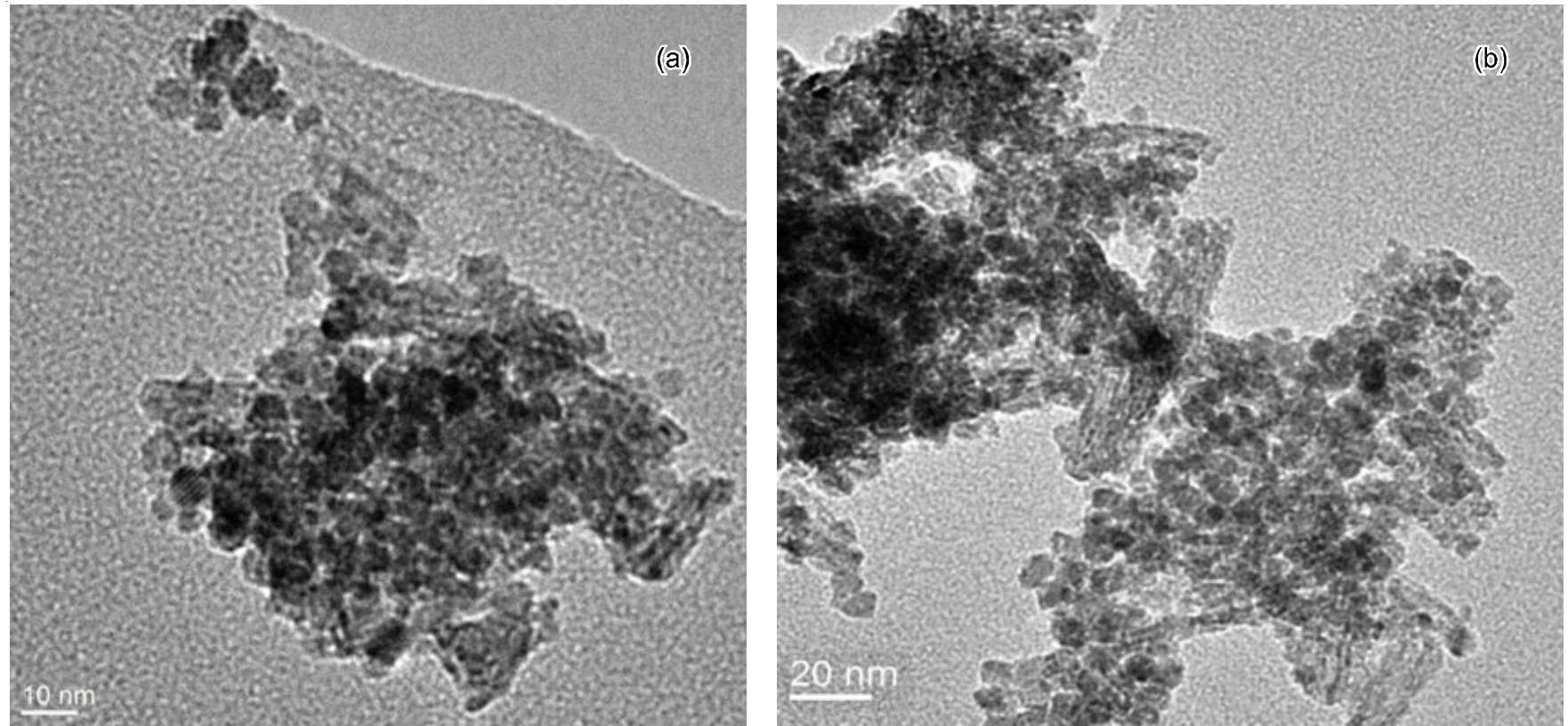

Fig. 4. TEM images of (a) $3 \mathrm{~mol} \% \mathrm{Mn}-\mathrm{CeO}_{2}$ (b) $5 \mathrm{~mol} \% \mathrm{Mn}-\mathrm{CeO}_{2}$

of UV-visible absorption spectroscopic studies revealed that Mn doping results into the red shift of absorption edge. Literature attributes the decrease in band gap on doping to the creation of oxygen vacancies, which favours conversion of $\mathrm{Ce}(\mathrm{IV})$ ions to $\mathrm{Ce}(\mathrm{III})$ ions. Increase in the concentration of $\mathrm{Ce}(\mathrm{III})$ ions creates the localized energy states which are closer to conduction band which decrease the band gap [7].

Photocatalytic activity: The spectroscopic analysis of the aliquot collected from the reaction mixture of photocatalyst and dye solution after attainment of adsorption-desorption equilibrium revealed that nearly $3 \%$ of remazol brilliant blue $\mathrm{R}$ was decreased by $5 \mathrm{~mol} \% \mathrm{Mn}$-doped $\mathrm{CeO}_{2}$ nanoparticles. Further, the periodical spectroscopic analysis of aliquot after the exposure of reaction mixture to solar or UV radiation are shown in Fig. 6(a-f). The analysis revealed a gradual decrease in the absorbance intensity with time. A decrease in the concentration of dye in the solution is due to photocatalytic degradation. The photocatalytic efficiency of pure $\mathrm{CeO}_{2}$ nanoparticles was found to be 39.4 and $43.2 \%$ under visible and UV irradiation respectively (Fig. 6a-b). Mn-doped $\mathrm{CeO}_{2}$ nanoparticles (3 and $5 \mathrm{~mol} \%$ ), on the other hand, exhibited higher efficiency of photo- catalytic degradation under visible as well as UV irradiation. In case of $3 \mathrm{~mol} \% \mathrm{Mn}$-doped $\mathrm{CeO}_{2}$ nanoparticles, the observed efficiency was 61.7 and $62.4 \%$ under and UV irradiation, respectively (Fig. 6c-d). The highest efficiency was observed for 5 mol \% Mn-doped $\mathrm{CeO}_{2}$ nanoparticles. It was found to be 62.45 and $67.7 \%$ for photocatalytic degradation under visible and UV irradiation, respectively (Fig. 6e-f). Fig. 7(a-b) shows the time dependent profiles of $\left(\mathrm{C} / \mathrm{C}_{\mathrm{o}}\right)$ of remazol brilliant blue $\mathrm{R}$ degradation under visible and UV irradiation. It revealed the faster degradation of remazol brilliant blue $\mathrm{R}$ in presence of $\mathrm{Mn}$-doped $\mathrm{CeO}_{2}$ nanoparticles under visible as well as UV irradiation.

Possible photocatalysis mechanism: Origin of photocatalytic degradation lies in the fact that upon excitation with photons of sufficient energy, the electron from valence band of photocatalyst jump to the conduction band, leaving behind a positive hole in the valence band. These charge carriers migrate to the surface of the catalyst, interact with the adsorbed species and initiate redox reactions leading to photocatalysis. The surface interaction of charge carriers with the adsorbed species can take place in a number of ways. Positive holes can interact with 

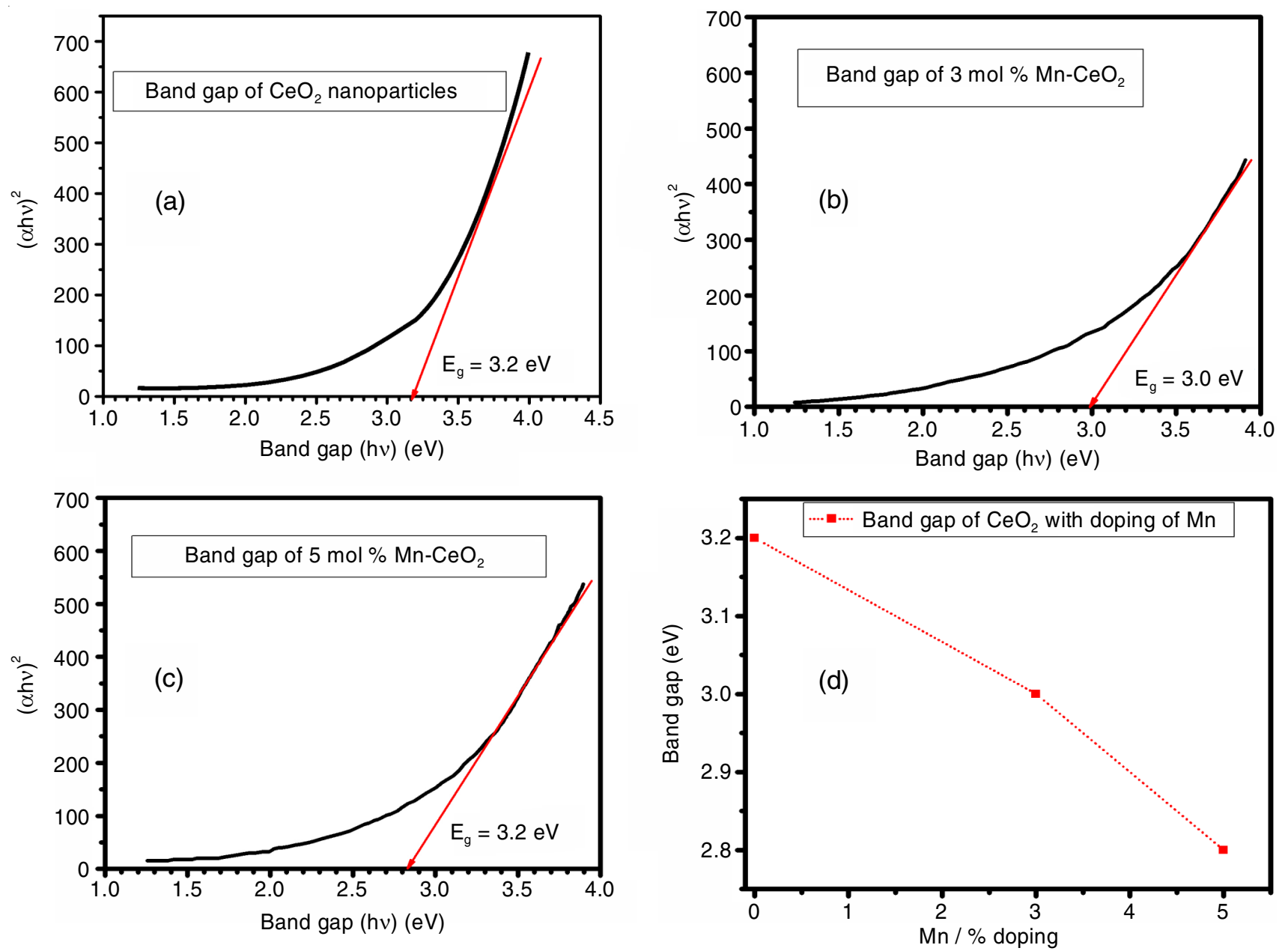

Fig. 5. Optical Band gap of pure and $\mathrm{Sr}$-doped $\mathrm{CeO}_{2}$ nanoparticles by Tauc Plot method (a) pure $\mathrm{CeO}_{2}$ (b) 3 mol $\% \mathrm{Mn}-\mathrm{doped} \mathrm{CeO}_{2}$ (c) 5 mol $\%$ Mn-doped $\mathrm{CeO}_{2}$ (d) Decrease in bandgap with Mn-doping
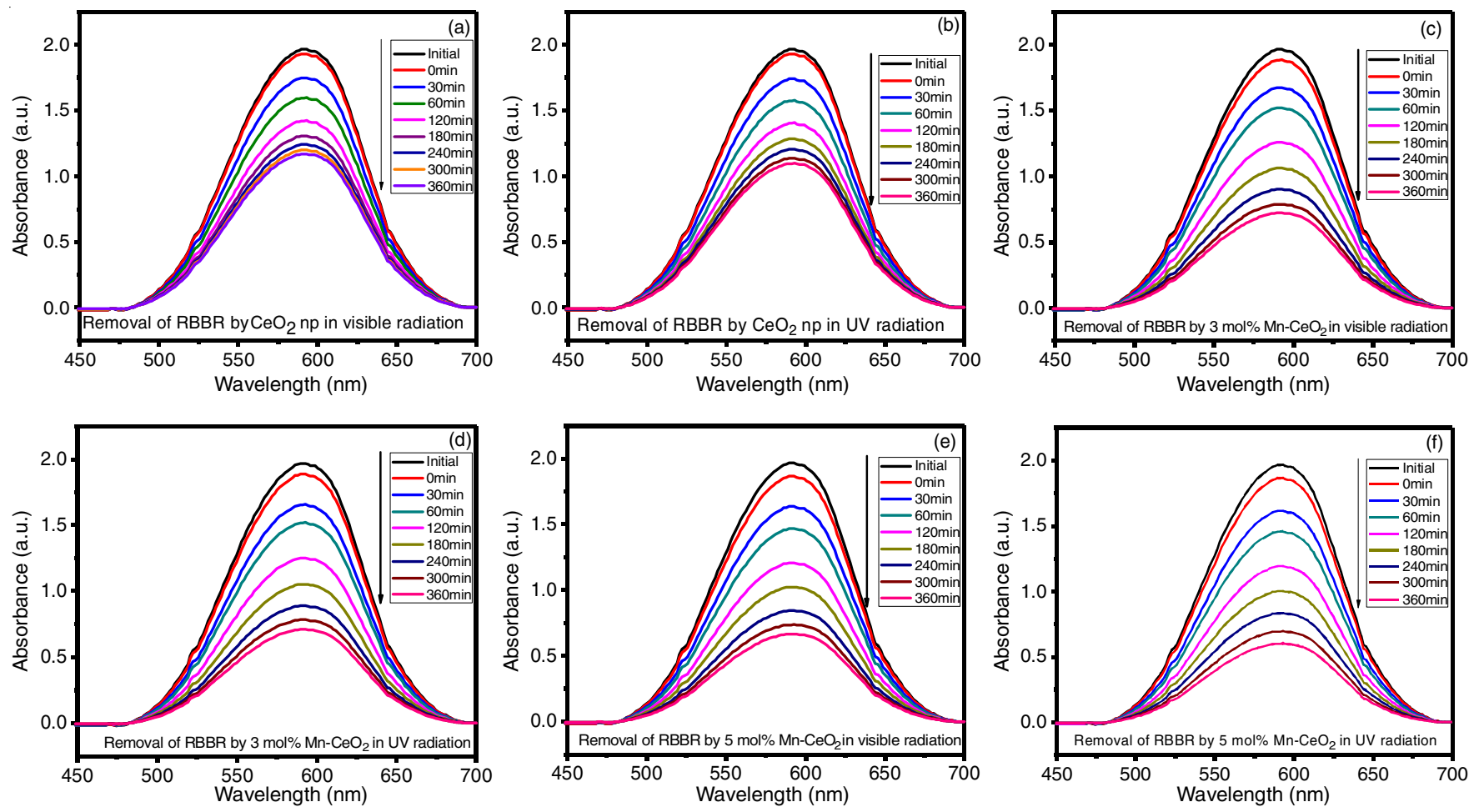

Fig. 6. UV-visible spectra showing RBBR degradation with respect to time in the presence of (a, b) undoped $\mathrm{CeO}_{2} \mathrm{NPs}_{\text {, }}(\mathrm{c}$, d) $3 \mathrm{~mol} \% \mathrm{Mn}$ $\mathrm{CeO}_{2}$ and (e, f) $5 \mathrm{~mol} \% \mathrm{Mn}-\mathrm{CeO}_{2} \mathrm{NPs}$ under visible and UV irradiation, respectively 


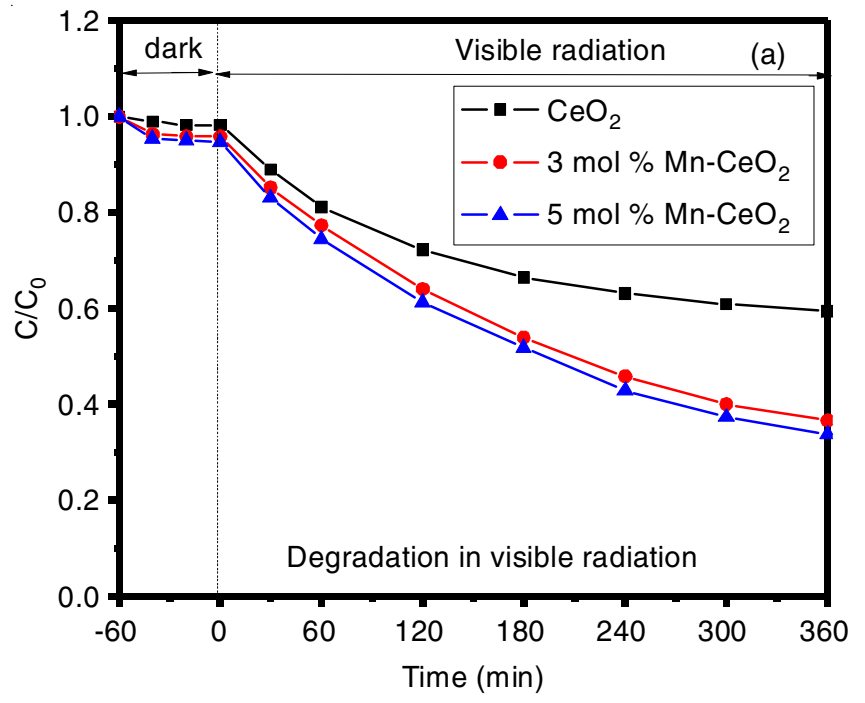

Fig. 7. Photocatalytic degradation rates of RBBR under

water forming strong oxidizing hydroxyl free radicals $\left({ }^{\circ} \mathrm{OH}\right)$, which in turn can oxidize adsorbed dye molecules. On the other hand, electrons in the conduction band can combine with oxygen molecules present at the surface of catalyst reducing it to superoxide ion $\left(\mathrm{O}_{2}^{-}\right)$. This species may undergo secondary reactions to form other reactive species viz. hydroperoxyl radical $\left({ }^{\circ} \mathrm{OOH}\right)$ and $\mathrm{H}_{2} \mathrm{O}_{2}$. These initiate various oxidative paths for dye degradation [26]. In the present case, doping of Mn ions to $\mathrm{CeO}_{2}$ matrix leads to decrease in band gap. The various precedents show that this fact, in turn, facilitates photogeneration of charge carriers (electron and hole) by exciting the electron from valence band to conduction band even by visible radiation in doped nanoparticles [16,27]. These charge carriers i.e. electron in conduction band and hole in valence band migrate towards the catalyst surface and participate in surface reactions to give oxidizing species. The photocatalyst surface is reported to follow Langmuir theory of unimolecular adsorption, photogenerated oxidizing species are confined to the surface of photocatalyst and they are unable to move far from it. As a result of which photocatalytic degradation takes place at the surface or within a few monolayers around it [28]. A similar mechanism of photocatalytic degradation of remazol brilliant blue R are shown in Scheme-I.

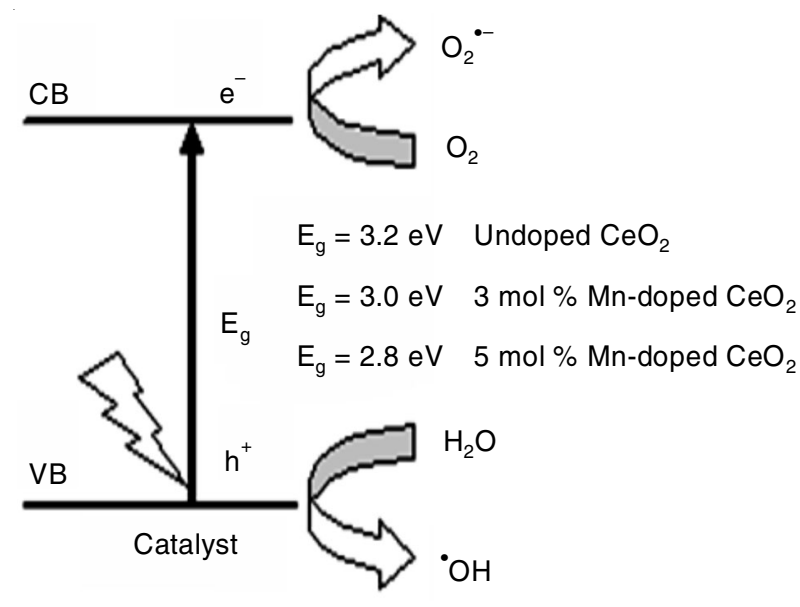

Scheme-I

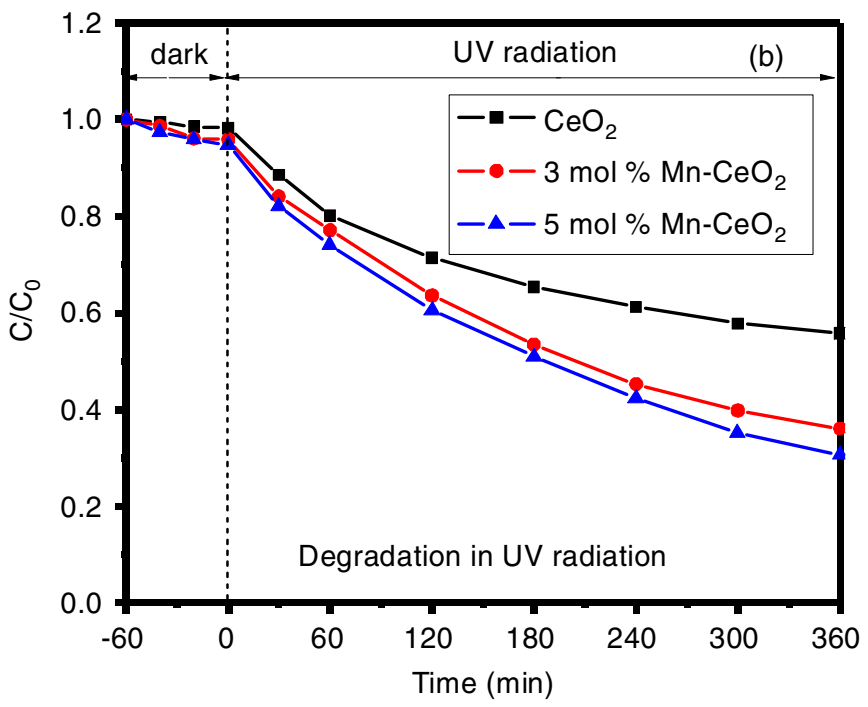

(a) visible and (b) UV irradiation for different photocatalyst

\section{Conclusion}

Mn-doped $\mathrm{CeO}_{2}$ nanoparticles ( 3 and $5 \mathrm{~mol} \%$ ) are successfully synthesised by aqueous coprecipitation method. The size of the synthesized nanoparticles varied in the range $12-15 \mathrm{~nm}$. The dopant concentration was found to be associated with the size and band gap of the nanoparticles. Increase in the concentration of Mn led to decrease in the size as well as band gap of nanoparticles. This narrowing of the band gap is reflected in the increased photocatalytic efficiency of $\mathrm{Mn}$-doped $\mathrm{CeO}_{2}$ nanoparticles under $\mathrm{UV}$ as well as visible radiation. The enhancement in the photocatalytic efficiency of $\mathrm{Mn}$-doped $\mathrm{CeO}_{2}$ may be attributed to the faster transportation of charge carriers from valence to conduction band due to the decrease in band gap. The doping of $\mathrm{Mn}$ ions into $\mathrm{CeO}_{2}$ matrix thus, makes the nanoparticles superior photocatalyst under visible as well as UV irradiation.

\section{CONFLICT OF INTEREST}

The authors declare that there is no conflict of interests regarding the publication of this article.

\section{REFERENCES}

1. Y. Wang, Z. Wang, S. Muhammad and J. He, CrystEngComm, 14, 5065 (2012);

https://doi.org/10.1039/c2ce25517k.

2. S. Higashimoto, Y. Tanaka, R. Ishikawa, S. Hasegawa, M. Azuma, H. Ohue and Y. Sakata, Catal. Sci. Technol., 3, 400 (2013); https://doi.org/10.1039/C2CY20607B.

3. A. Trovarelli, C. De Leitenburg, M. Boaro and G. Dolcetti, Catal. Today, 50, 353 (1999); https://doi.org/10.1016/S0920-5861(98)00515-X.

4. R.X. Li, S. Yabe, M. Yamashita, S. Momose, S. Yoshida, S. Yin and T. Sato, Solid State Ion., 151, 235 (2002);

https://doi.org/10.1016/S0167-2738(02)00715-4.

5. T. Masui, H. Hirai, R. Hamada, N. Imanaka, G. Adachi, T. Sakata and H. Mori, J. Mater. Chem., 13, 622 (2003); https://doi.org/10.1039/b208109a.

6. I. Liu, M.H. Hon and L.G. Teoh, J. Electron. Mater, 42, 2536 (2013); https://doi.org/10.1007/s11664-013-2617-9.

7. J. Saranya, K.S. Ranjith, P. Saravanan, D. Mangalaraj and R.T. Rajendra Kumar, Mater. Sci. Semicond. Process., 26, 218 (2014); https://doi.org/10.1016/j.mssp.2014.03.054.

8. T. Herrling, M. Seifert and K. Jung, SOFW J., 139, 12 (2013). 
9. H.R. Pouretedal and A. Kadkhodaie, Chin. J. Catal., 31, 1328 (2010); https://doi.org/10.1016/S1872-2067(10)60121-0.

10. R.M. Mohamed and E.S. Aazam, Int. J. Photoenergy, Article ID 137328 (2011); https://doi.org/10.1155/2011/137328.

11. A.B. Sifontes, M. Rosales, F.J. Méndez, O. Oviedo and T. Zoltan, J. Nanomater, 2013, 1 (2013); https://doi.org/10.1155/2013/265797.

12. A. Akbari-Fakhrabadi, R. Saravanan, M. Jamshidijam, R.V. Mangalaraja and M.A. Gracia, J. Saudi Chem. Soc., 19, 505 (2015); https://doi.org/10.1016/i.jscs.2015.06.003.

13. W. Li, R. Liang, A. Hu, Z. Huang and Y.N. Zhou, RSC Adv., 4, 36959 (2014); https://doi.org/10.1039/C4RA04768K.

14. A.D. Liyanage, S.D. Perera, K. Tan, Y. Chabal and K.J. Balkus Jr., ACS Catal., 4, 577 (2014); https://doi.org/10.1021/cs400889y.

15. D. Channei, B. Inceesungvorn, N. Wetchakun, S. Ukritnukun, A. Nattestad, J. Chen and S. Phanichphant, Sci. Rep., 4, 5757 (2014); https://doi.org/10.1038/srep05757.

16. A. Primo, T. Marino, A. Corma, R. Molinari and H. García, J. Am. Chem. Soc., 133, 6930 (2011); https://doi.org/10.1021/ja2011498.

17. H. Liang, J.M. Raitano, G. He, A.J. Akey, I.P. Herman, L. Zhang and S.-W. Chan, J. Mater. Sci., 47, 299 (2012); https://doi.org/10.1007/s10853-011-5798-8.

18. J. Tan, W. Zhang, Y.-H. Lv and A.-L. Xia, Mater. Res., 16, 689 (2013); https://doi.org/10.1590/S1516-14392013005000040.
19. L. Yue and X.M. Zhang, J. Alloys Compd., 475, 702 (2009); https://doi.org/10.1016/j.jallcom.2008.07.096.

20. T. Montini, M. Melchionna, M. Monai and P. Fornasiero, Chem. Rev., 116, 5987 (2016); https://doi.org/10.1021/acs.chemrev.5b00603.

21. F. Herrera, J. Kiwi, A. Lopez and V. Nadtochenko, Environ. Sci. Technol., 33, 3145 (1999); https://doi.org/10.1021/es980995+.

22. D. Özçimen and T. Salan, In Proceedings of EurAsia Waste Management Symposium, Turkey, p. 1042 (2014).

23. M. Farahmandjou, M. Zarinkamar and T.P. Firoozabadi, Rev. Mex. Fis., 62, 496 (2016).

24. C.H.S.S.P. Kumar, R.J.B. Balaguru and B.G. Jeyaprakas, J. Appl. Sci., 12, 1738 (2012); https://doi.org/10.3923/jas.2012.1738.1741.

25. A. Ramadoss and S.J. Kim, J. Alloys Compd., 544, 115 (2012); https://doi.org/10.1016/j.jallcom.2012.08.005.

26. T. Tachikawa, M. Fujitsuka and T. Majima, J. Phys. Chem. C, 111, 5259 (2007); https://doi.org/10.1021/ip069005u.

27. Y. Sun, B. Qu, Q. Liu, S. Gao, Z. Yan, W. Yan, B. Pan, S. Wei and Y. Xie, Nanoscale, 4, 3761 (2012); https://doi.org/10.1039/c2nr30371j.

28. M. Chatti, V.N.K.B. Adusumalli, S. Ganguli and V. Mahalingam, Dalton Trans., 45, 12384 (2016); https://doi.org/10.1039/C6DT02548J. 